\title{
Kapabilitas Membangun Jaringan dengan Pemasok untuk Meningkatkan Kinerja Operasional Pada Toko Aksesoris Telepon Genggam Di Kabupaten Banyumas
}

\author{
Sri Sundari*, Cahyaningtyas Ria Uripi \\ Fakultas Ekonomika dan Bisnis Universitas Wijayakusuma Purwokerto \\ *correspondence email: ssundari.ku@gmail.com, cahyaurry@yahoo.co.id
}

\begin{abstract}
Abstrak. Semakin meningkatnya kebutuhan terhadap telepon genggam mengakibatkan semakin pesat perkembangan bisnis aksesoris telepon genggam di Kabupaten Banyumas. Persaingan antar toko aksesoris mengakibatkan pentingnya kinerja operasional agar dapat menjaga kelangsungan hidupnya. Untuk dapat mencapai kinerja operasional yang unggul, toko aksesoris telepon genggam harus memiliki kapabilitas membangun jaringan dengan pemasok. Penelitian ini bertujuan meneliti pengaruh kapabilitas membangun jaringan dengan pemasok (terdiri dari tiga dimensi, yaitu developing effective network structures, supplier base reduction dan longterm orientation) dan kinerja operasional pemasok terhadap kinerja operasional toko aksesoris telepon genggam.Penelitian ini merupakan penelitian survey dengan populasi toko aksesoris telepon genggam di Kabupaten Banyumas dan ukuran sampel sebanyak 100 responden. Metode analisis dan pengujian hipotesis menggunakan Structural Equation Model (SEM) dengan menggunakan program AMOS 22. Dari hasil pengujian menunjukkan bahwa Developing effective network structures berpengaruh positif terhadap supplier operational performance, Supplier base reduction berpengaruh positif terhadap supplier operational performance, Longterm orientation berpengaruh positif terhadap supplier operational performance, Supplier operational performance berpengaruh positif terhadap organization operational performance. Implikasi dari penelitian ini adalah perlu peningkatan menjalin jaringan yang efektif antara toko aksesoris telepon genggam dengan pemasok agar kinerja operasional unit bisnisnya meningkat.
\end{abstract}

Kata Kunci: developing effective network structures, supplier base reduction, longterm orientation, supplier operational performance, organization operational performance.

Abstract. The increasing need for mobile phones has resulted in the rapid development of the mobile phone accessories business in Banyumas Regency. Competition between accessories stores results in the importance of operational performance in order to maintain its survival. To be able to achieve superior operational performance, a mobile phone accessories shop must have the capability to build a network with suppliers. This study aims to examine the effect of the capability of building a network with suppliers (consisting of three dimensions, namely developing effective network structures, supplier base reduction and longterm orientation) and supplier operational performance on the operational performance of mobile phone accessories stores.This research is a survey research with a population of mobile phone accessories stores in Banyumas Regency and a sample size of 100 respondents. The method of analysis and hypothesis testing uses the Structural Equation Model (SEM) using the AMOS 22 program. From the test results it can be concluded that developing effective network structures has a positive effect on supplier operational performance, Supplier base reduction has a positive effect on supplier operational performance, Longterm orientation has a positive effect on supplier operational performance. supplier operational performance, supplier operational performance has a positive effect on organization operational performance. The implication of this research is that there is a need to increase in establishing an effective network between mobile phone accessories stores and suppliers so that the operational performance of the business units increases.

Keywords: developing effective network structures, supplier base reduction, longterm orientation, supplier operational performance, organization operational performance.

\section{PENDAHULUAN}

Telepon genggam telah menjadi kebutuhan utama sebagai alat komunikasi. Semakin bertambahnya fungsi telepon genggam, maka kebutuhan akan telepon genggam semakin meningkat. Bertambahnya pengguna telepon genggam mengakibatkan bisnis aksesoris telepon genggam semakin meningkat. Perkembangan bisnis aksesoris telepon genggam di Kabupaten Banyumas semakin marak. Hal tersebut dibuktikan dengan semakin menjamurnya toko aksesoris telepon genggam hampir disemua penjuru jalan di wilayah Kabupaten Banyumas. Persaingan antar toko aksesoris tersebut mengakibatkan pentingnya kinerja perusahaan, agar dapat menjaga kelangsungan hidupnya. Agar dapat memenuhi kebutuhan dan keinginan konsumen dengan baik, kapabilitas membangun jaringan dengan pemasok sangat penting, hal tersebut dapat meningkatkan kinerja operasional perusahaan (Ziggers and Henseler, 2009). Teori Capability Based View (CBV) yang dikemukakan oleh Day pada tahun 1992 memberikan kontribusi dalam menjelaskan pengaruh kapabilitas organisasi terhadap kinerja perusahaannya. Beberapa peneliti telah menggunakan logika dari konsep CBV sebagai dasar teori dalam penelitiannya. Kapabilitas menurut Day (1994) merupakan kumpulan ketrampilan dan akumulasi pengetahuan yang memungkinkan perusahaan untuk mengkoordinasikan kegiatan dan memanfaatkan sumber daya mereka. Kapabilitas merupakan perekat dari semua 
sumber daya perusahaan sehingga dapat digunakan untuk mencapai keuntungan.

$$
\text { Pemasok merupakan sumber daya yang }
$$

memungkinkan perusahaan untuk melakukan konsolidasi atau meningkatkan kompetensi internal dan bersaing secara lebih efektif di pasar. Persaingan usaha yang semakin kuat, serta perkembangan teknologi yang kuat menuntut perusahaan agar dapat melayani kebutuhan dan keinginan konsumen dengan cepat. Agar dapat memenuhi kebutuhan dan keinginan konsumen dengan baik, kapabilitas membangun jaringan dengan pemasok sangat penting, hal tersebut dapat meningkatkan kinerja operasional perusahaan (Ziggers and Henseler, 2009). Kapabilitas membangun jaringan dengan pemasok memungkinkan perusahaan untuk mengungguli pesaing mereka dalam banyak aspek dan dapat berkontribusi pada kinerja pasar yang unggul. Kapabilitas tersebut terdiri dari kapabilitas membina hubungan erat dengan beberapa pemasok, kapabilitas membangun jaringan yang efektif, kapabilitas menjalin hubungan jangka panjang yang saling menguntungkan (Chen and Paulraj, 2004). Hubungan dengan pemasok merupakan sumber keunggulan bersaing, dimana perusahaan dapat meningkatkan inovasi, pengurangan biaya, dan meningkatkan respon pelanggan (Chen and Paulraj, 2004).

Kapabilitas membangun jaringan dengan pemasok adalah kemampuan perusahaan membina hubungan erat dengan pemasok, membangun struktur jaringan yang efektif, dan mengembangkan orientasi hubungan jangka panjang (Ziggers and Henseler, 2009). Fokus kapabilitas membangun jaringan adalah menciptakan nilai yang unggul atas dasar koordinasi dan pengetahuan yang berasal dari jaringan antar perusahaan. Perusahaan dengan kapabilitas membangun jaringan tinggi akan memprioritaskan hubungannya dengan membangun struktur jaringan yang efektif, membina hubungan yang erat dengan pemasok tertentu dan mengembangkan hungungan jangka panjang untuk mencapai keuntungan bersama. Kapabilitas membangun jaringan dengan pemasok terdiri dari tiga dimensi, yaitu developing effective network structures, supplier base reduction, longterm orientation.

Kapabilitas membangun jaringan menunjukkan beberapa karakteristik utama Resource Based View (Barney, 1991) yaitu pertama valueable dimana manfaatnya tidak akan berkurang ketika digunakan. Kedua, inimitable karena proses untuk mengembangkan kapabilitas membangun jaringan tertanam dalam rutinitas kognitif yang tidak dapat diamati oleh pesaing. Ketiga, immobile karena prosesnya dibuat di dalam perusahaan atau di antara perusahaan, tidak dapat dibeli di pasar terbuka. Keempat, rare karena prosesnya tidak dimiliki oleh pesaing. Sebagai perusahaan yang memiliki sumber daya dan empat atribut ini akan mencapai keunggulan kompetitif yang berkelanjutan.
Agar dapat mencapai kinerja operasionalnya, toko aksesoris telepon genggam sebagai unit bisnis harus memiliki kapabilitas membangun jaringan dengan pemasok agar dapat mencapai kinerja operasional yang unggul. Penelitian ini bertujuan meneliti pengaruh kapabilitas membangun jaringan dengan pemasok dan kinerja operasional pemasok terhadap kinerja operasional toko aksesoris telepon genggam. Dengan maraknya bisnis aksesoris telepon genggam di Kabupaten Banyumas maka penelitian ini sangat relevan.

\section{Tinjauan Pustaka}

\section{Capability Based View (CBV)}

Capability Based View dicetuskan oleh Day pada tahun 1992 untuk melengkapi teori Resource Based View (Wenerfelt, 1984) dari konsep sumberdaya dengan kapabilitas. Kapabilitas berfungsi untuk mengintegrasikan kegiatan, tindakan dan proses dalam memanfaatkan sumberdaya tersebut. Kapabilitas adalah sumberdaya khusus yang digunakan untuk meningkatkan produktivitas sumberdaya yang dimiliki oleh perusahaan.

Lingkungan persaingan yang semakin hari semakin dinamis, menuntut organisasi merespon dengan cepat perubahan lingkungan persaingan tersebut dengan kapabilitas baru agar dapat mencapai keunggulan bersaing. Pada tahun 1997 Teece mencetuskan konsep dynamic capabilities untuk merespon lingkungan persaingan yang semakin dinamis. Dynamic capabilities terdiri tiga kegiatan utama, yaitu :

1. Sense and shape (merasakan dan membentuk) peluang dan ancaman

2. Seize meraih atau menangkap peluang
3. Maintain
competitiveness
(mempertahankan keunggulan)

Ada empat proses utama dalam dynamic capabilities yaitu :

1. Reconfiguration (konfigurasi ulang) yaitu proses transformasi dan kombinasi ulang aset-aset dan sumber-sumberdaya organisasi.

2. Leveraging (mengungkit) yaitu proses replikasi sistem yang berada pada suatu area ke dalam area lain di perusahaan atau meningkatkan sumberdaya dengan cara dengan menyebarkannya kedalam domain baru,

3. Learning (pembelajaran) yaitu proses melaksanakana tugas dan pekerjaan dengan efektif dan efisien.

4. Integration (integrasi) yaitu proses menggabungkan dan mengkoordinasikan sumberdaya dan aset yang dimilikinya agar menghasilkan basis sumberdaya baru.

\section{Network Capability}

Sebuah perusahaan perlu untuk melakukan hubungan agar dapat melakukan pengembangan. 
Network capability adalah kemampuan perusahaan untuk mencari dan menemukan, mengelola dan memanfaatkan ikatan, kontak dan koneksi dengan pihak lain dari waktu ke waktu, berkembang dan tumbuh melalui jaringan yang mereka bangun (Mort \& Weerawardena, 2006). Dengan kata lain, network capability adalah kemampuan perusahaan untuk mengeksploitasi ikatan sosial, kontak dan koneksi dengan pihak lain untuk mendorong dan menyebarkan sumberdaya jaringan untuk penciptaan nilai tambah. Hal tersebut dapat dilakukan melalui hubungan dengan perusahaan lain agar mendapatkan akses sumberdaya dan kapabilitas. Sumberdaya dan kapabilitas dari luar tersebut dapat mempengaruhi kinerja perusahaan Kapabilitas membangun jaringan (network capability) adalah kemampuan perusahaan untuk memulai, mengembangkan dan memanfaatkan hubungan eksternal antar organisasi (Zacca et al., 2015). Menurut Ziggers and Henseler (2009), Network capability terdiri dari developing effective network structure, supplier base reduction, longterm orientation.

\section{Developing effective network structures}

Lingkungan persaingan yang semakin dinamis menuntut perusahaan untuk memiliki sumberdaya dan kapabilitas baru dapat bersaing dengan pesaing. Pada kondisi lingkungan yang dinanis, perusahaan yang mampu menciptakan jaringan yang kuat akan lebih mampu memposisikan diri di pasar yang kompetitif dan mempertahankan keunggulannya. Jaringan memungkinkan perusahaan untuk mempercepat akses dan transfer pengetahuan, yang memiliki pengaruh pada inovasi dan pertumbuhan perusahaan. Jaringan yang kuat memungkinkan interaksi dengan perusahaan lain sehingga ada transfer pengetahuan dari perusahaan tersebut. Faktor penting dalam membangun jaringan dengan pemasok yang efektif adalah hubungan yang kuat antara pihak yang membangun jaringan, saling ketergantungan satu sama lain, dan melakukan hubungan atas dasar saling menguntungkan tanpa dasar kekuasaan. Membangun struktur jaringan yang efektif adalah sejauh mana perusahaan menekankan pada hubungan yang tidak berbasis kekuasaan dan koordinasi antar perusahaan tertanam dalam sistem informal (Chen, 2004).

\section{Supplier Base Reduction}

Supplier Base Reduction adalah pengurangan atau pembatasan jumlah pemasok oleh perusahaan. Banyak perusahaan mengurangi jumlah pemasok utama dan mengalokasikan sebagian besar pasokan yang dibeli ke satu sumber. Pada saat yang lalu perusahaan biasanya mengontrak sejumlah besar pemasok. Pada saat ini telah terjadi pergeseran yang signifikan pada hubungan antara pembeli dan penjual dari konsep tradisional ke penggunaan sejumlah pemasok yang berkualitas (Burt, 1989; Helper, 1991). Manfaat adanya supplier base reduction adalah:
1. Lebih sedikit pemasok untuk dihubungi jika ada pesanan yang mendadak.

2. Mengurangi biaya manajemen persediaan (Trevelen, 1987)

3. Konsolidasi tentang volume pembelian dan diskon menjadi lebih baik.

4. Peningkatan skala ekonomi berdasarkan volume pesanan (Hahn et al,, 1986)

5. Mengurangi waktu tunggu mengurangi biaya logistik (Bozarth et al.,1998),

6. Koordinasi yang baik (Russell dan Krajewski, 1992),

7. Tersedianya hubungan dalam desain produk antara pembeli dan pemasok yang lebih baik (De Toni dan Nassimbeni, 1999),

8. Meningkatnya kepercayaan karena komunikasi yang baik

9. Meningkatan kinerja (Shin et al., 2000)

10. Adanya layanan pelanggan dan penetrasi pasar yang lebih baik (St.John dan Heriot, 1993).

\section{Longterm orientation}

Kapabilitas membangun jaringan memungkin perusahaan untuk berbagi resiko dan keuntungan serta menjalin hubungan dalam jangka panjang. Menurut Hahn et al. (1983) perusahaan akan mendapatkan keuntungan dengan menempatkan volume bisnis yang lebih besar menggunakan lebih sedikit pemasok yang menggunakan kontrak jangka panjang. Hubungan dalam perspektif jangka panjang antara pembeli dan pemasok akan meningkatkan intensitas koordinasi pembelipemasok, selain itu hubungan jangka panjang ini memiliki dampak positif pada kinerja pemasok perusahaan. Melalui hubungan jangka panjang, pemasok akan menjadi bagian dari rantai yang dikelola dengan baik dan akan memiliki pengruh pada daya saing seluruh rantai pasokan (Kotabe et al., 2003).

\section{Hipotesis}

1. Developing effective network structures berpengaruh positif terhadap supplier operational performance

2. Supplier base reduction berpengaruh positif terhadap supplier operational performance

3. Longterm orientation berpengaruh positif terhadap supplier operational performance

4. Supplier operational performance berpengaruh positif terhadap organization operational performance

\section{METODE}

Penelitian ini adalah penelitian survey yaitu penelitian yang tidak memberikan perlakuan kepada subyek penelitian (Suliyanto, 2006). Lokasi penelitian adalah toko aksesoris telepon genggam di Kabupaten Banyumas. Populasi penelitian adalah toko aksesoris telepon genggam di Kabupaten Banyumas yang populasinya tidak diketahui. Ukuran sampel penelitian sejumlah 100 responden. Data Primer diperoleh langsung dari jawaban responden terhadap pertanyaan. 
Sri Sundari dan Cahyaningtyas Ria Uripi, Kapabilitas Membangun Jaringan dengan Pemasok untuk Meningkatkan Kinerja Operasional Pada Toko Aksesoris Telepon Genggam Di Kabupaten Banyumas

Data Sekunder diperoleh dari literatur, jurnal, penelitian terdahulu dan dokumen lain yang diperlukan dalam penelitian ini.

Variabel dalam penelitian ini ada 5 (lima) yaitu developing effective network, supplier base reduction, longterm orientation, supplier operational performance dan organization operational performance. Definisi konseptual dan definisi operasional beserta indikatornya sebagai berikut :

Tabel 1. Definisi konseptual dan definisi operasional variabel

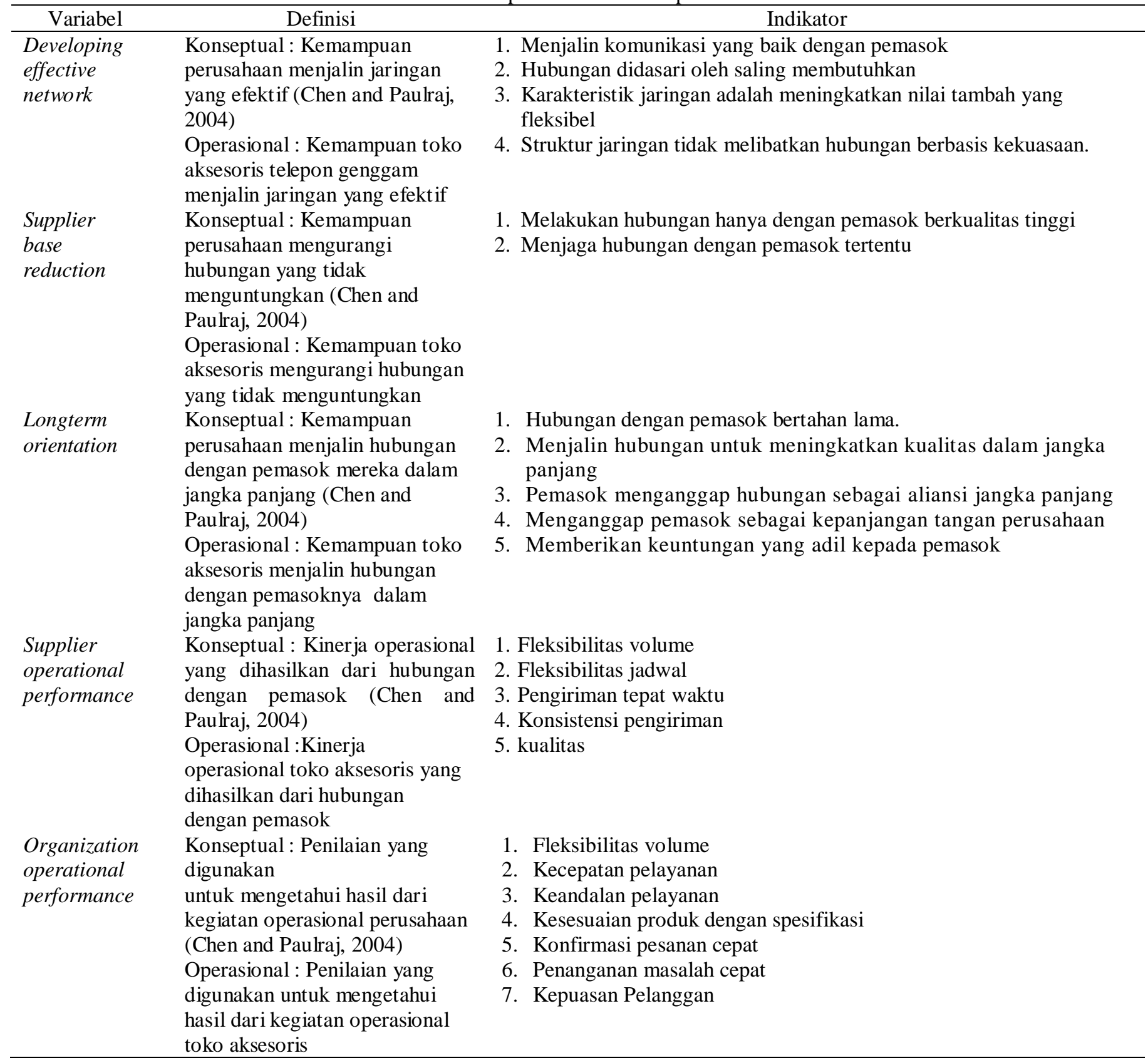

Metode analisis dan pengujian hipotesis menggunakan Structural Equation Model (SEM) dengan menggunakan program AMOS 22. Dalam pengujian model dengan menggunakan SEM, terdapat tujuh langkah yang harus ditempuh (Ferdinand, 2005), dalam penelitian ini menggunakan path diagram sebagai berikut: 


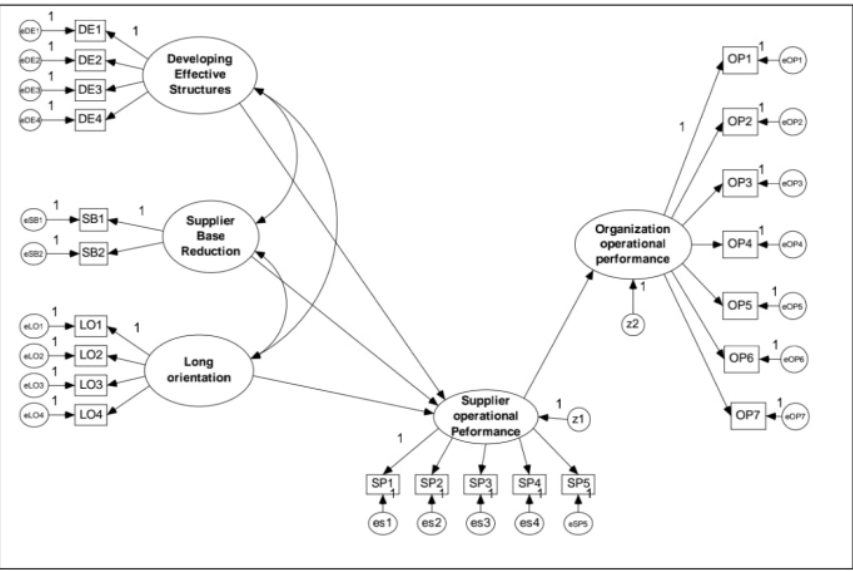

Gambar 1. Path Diagram

\section{HASIL DAN PEMBAHASAN \\ Analisa Deskriptif}

Analisis ini dimaksudkan untuk mengetahui distribusi frekuensi jawaban responden dari daftar pertanyaan yang disebarkan dan berisikan variabel Developing effective network, Supplier base reduction, Longterm orientation, Supplier Operation Performance dan Organization Operational Performance. Distribusi jawaban responden pada masing-masing variabel didasarkan pada kategori sebagaimana dalam Tabel 2. Kategori penilaian jawaban responden dibuat melalui rentang skor maksimum dengan skor minimum dibagi jumlah kategori yang diinginkan yaitu 5 kriteria (Sugiyono, 2005).

Tabel 2. Standar kategori penilaian jawaban responden

\begin{tabular}{cl}
\hline Skala Interval & \multicolumn{1}{c}{ Kategori } \\
\hline $1,00-2,20$ & Sangat Rendah/ Tidak baik \\
$2,21-3,40$ & Rendah/ Kurang baik \\
$3,41-4,60$ & Cukup/ Cukup baik \\
$4,61-5,80$ & Tinggi/Baik \\
$5,81-7,00$ & Sangat tinggi/ Sangat baik \\
\hline
\end{tabular}

Analisa statistik deskriptif untuk distribusi frekuensi jawaban responden atas variabel Developing effective network, Supplier base reduction, longterm orientation, Supplier Operation Performance dan Organization Operational Performance sebagai berikut

\section{Variabel Developing effective network}

Dalam variabel Developing effective network ini ada lima indikator yang digunakan. Rata-rata jawaban responden adalah sebesar 5,13 . Hal ini menunjukkan bahwa kategori jawaban responden atas variabel Developing effective network adalah tinggi/baik. Dengan demikian variabel Developing effective network ini perlu ditingkatkan lagi agar menjadi sangat baik.

\section{Variabel Supplier base reduction}

Dalam variabel Supplier base reduction ini ada lima indikator yang digunakan. Rata-rata jawaban responden adalah sebesar 4,97. Hal ini menunjukkan bahwa skor kategori jawaban responden atas variabel Supplier base reduction adalah tinggi/baik. Dengan demikian variabel Supplier base reduction ini perlu ditingkatkan lagi agar menjadi sangat baik.

\section{Variabel longterm orientation}

Dalam variabel longterm orientation ini ada lima indikator yang digunakan. Rata- rata jawaban responden adalah sebesar 5,13. Hal ini menunjukkan bahwa skor kategori jawaban responden atas variabel longterm orientation adalah tinggi/baik. Dengan demikian variabel longterm orientation ini perlu ditingkatkan lagi agar menjadi sangat baik.

\section{Variabel supplier operational performance}

Dalam variabel supplier operational performance ini ada tiga indikator yang digunakan. Rata-rata jawaban responden adalah sebesar 5,21. Hal ini menunjukkan bahwa skor kategori jawaban responden atas variabel supplier operational performance adalah tinggi/baik. Dengan demikian variabel supplier operational performance ini perlu ditingkatkan lagi agar menjadi sangat baik.

\section{Variabel Organization operational performance}

Dalam variabel Organization operational performance ini ada empat indikator yang digunakan. Rata-rata jawaban responden adalah sebesar 5,16. Hal ini menunjukkan bahwa skor kategori jawaban responden atas variabel Organization operational performance adalah tinggi/baik. Dengan demikian variabel Organization operational performance ini perlu ditingkatkan lagi agar menjadi sangat baik.

\section{Analisis Data}

Analisa data pada penelitian ini menggunakan Structural Equation Modeling (SEM) dengan program AMOS 22.0. Dalam pengujian model dengan menggunakan SEM, terdapat tujuh langkah yang ditempuh, yaitu (Ferdinand, 2005):

\section{Pengembangan Model Berbasis Teori}

Tujuan dari penelitian ini menguji pengaruh Developing effective network, Supplier base reduction, Longterm orientation terhadap Supplier Operation Performance dan Organization Operational Performance toko aksesoris telepon genggam di Kabupaten Banyumas.

Model hubungan kausal diatas dibangun berdasarkan pada telaah pustaka baik tinjauan toritis maupun penelitian-penelitian empiris yang diakui kualitasnya.

\section{Penyusunan Path Diagram}

Berdasarkan pada model berbasis teori yang dikembangkan diatas maka tampilan model yang digambarkan dalam path diagram disajikan dalam 
Sri Sundari dan Cahyaningtyas Ria Uripi, Kapabilitas Membangun Jaringan dengan Pemasok untuk Meningkatkan Kinerja Operasional Pada Toko Aksesoris Telepon Genggam Di Kabupaten Banyumas

Gambar 3. Model ini memiliki konstruk eksogen dan endogen sebagai berikut:

1. Konstruk eksogen pertama : Developing effective network

Yang dihipotesiskan mempunyai pengaruh terhadap variabel Supplier Operation Performance yang dinyatakan sebagai variabel laten (unobserved variabel).

2. Konstruk eksogen kedua : Supplier base reduction Yang dihipotesiskan mempunyai pengaruh terhadap variabel Supplier Operation Performance yang dinyatakan sebagai variabel laten (unobserved variabel)

3. Konstruk eksogen ketiga : Longterm orientation Yang dihipotesiskan mempunyai pengaruh terhadap variabel Supplier Operation Performance yang dinyatakan sebagai variabel laten (unobserved variabel).

4. Konstruk endogen pertama : Supplier Operation Performance

Yang dihipotesiskan dipengaruhi oleh variabel Developing effective network, Supplier base reduction, Longterm orientation, yang dinyatakan sebagai variabel laten (unobserved variabel)

5. Konstruk endogen : Organization Operational Performance

Yang dihipotesiskan dipengaruhi oleh variabel Supplier Operation Performance yang dinyatakan sebagai variabel laten (unobserved variabel).

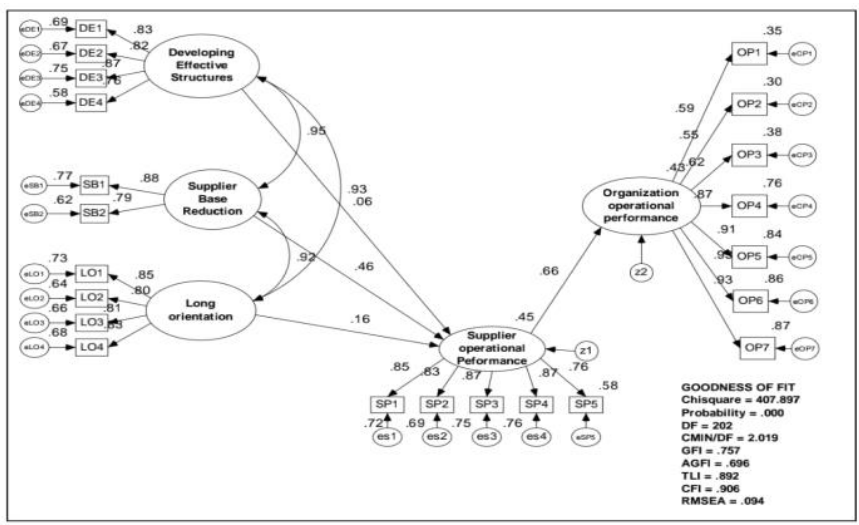

Gambar 3. Path Diagram Model Specification

\section{Menyusun Persamaan Struktural dan Measurement Model}

Model yang dinyatakan dalam path diagram diatas dinyatakan dalam dua kategori dasar persamaan.

1. Persamaan Pengukuran

Konstruk Eksogen Developing effective network

$\mathrm{DE} 1=0,83$ Developing effective network $+\mathrm{eDE} 1$

$D E 2=0,82$ Developing effective network $+\mathrm{eDE} 2$

$\mathrm{DE} 3=0,87$ Developing effective network $+\mathrm{eDE} 3$

DE4 $=0,76$ Developing effective network $+\mathrm{eDE} 4$

Konstruk Eksogen Supplier base reduction

$S B 1=0,88$ Supplier base reduction $+\mathrm{eSB} 1$

$S B 2=0,79$ Supplier base reduction $+\mathrm{eSB} 2$
Konstruk Eksogen longterm orientation

$\mathrm{LO} 1=0,85$ longterm orientation $+e \mathrm{LO} 1$

$\mathrm{LO} 2=0,80$ longterm orientation $+e \mathrm{LO} 2$

$\mathrm{LO} 3=0,81$ longterm orientation $+e \mathrm{LO} 3$

$\mathrm{LO} 4=0,83$ longterm orientation $+e \mathrm{LO} 4$

Konstruk Endogen supplier operational performance

$\mathrm{SP} 1=0,85$ supplier operational performance + eSP1

$\mathrm{SP} 2=0,83$ supplier operational performance + eSP2

$\mathrm{SP} 3=0,87$ supplier operational performance + eSP3

SP4 $=0,87$ supplier operational performance + eSP4

SP5 $=0,76$ supplier operational performance + eSP5

Konstruk Endogen Organization operational performance

OP1 $=0,59$ Organization operational performance $+\mathrm{eOP} 1$

$\mathrm{OP} 2=0,58$ Organization operational

performance $+\mathrm{eOP} 2$

OP3 $=0,62$ Organization operational

performance $+\mathrm{eOP} 3$

$\mathrm{OP} 4=0,87$ Organization operational performance $+\mathrm{eOP} 4$

OP5 $=091$ Organization operational performance + eOP5

OP6 = 093 Organization operational performance $+\mathrm{eOP} 6$

OP7 $=093$ Organization operational performance $+\mathrm{eOP} 7$

2. Persamaan Struktural

$$
\begin{aligned}
& \mathrm{SP}=0,06 \mathrm{DE}+0,46 \mathrm{SB}+0,16 \mathrm{LO}++\varepsilon \\
& \mathrm{OP}=0,60 \mathrm{SP}+\varepsilon
\end{aligned}
$$

\section{Memilih matriks Input dan Teknik Estimasi}

Uji yang dilakukan dalam penelitian ini adalah hubungan kausalitas, maka input yang digunakan adalah kovarian. Teknik estimasi yang digunakan adalah metode maximum likelihood estimation yang terdefault dalam program AMOS.

\section{Menilai Kemungkinan Munculnya Identification Problem}

Jika terdapat identification problem, program AMOS akan memberikan warning, sehingga pengguna akan melakukan langkah-langkah perbaikan. Tetapi jika program AMOS dapat dijalankan menunjukkan bahwa besaran standart error, varian error serta korelasi antar koefisien estimasi berada dalam rentang nilai yang tidak menunjukkan adanya problem identifikasi. 


\section{Analisis Konfirmatori Faktor (Confirmatory Factor Analysis)}

Proses penyusunan model persamaan struktural dimulai dari menentukan konstruk laten dengan Confirmatory Factor Analysis (CFA). CFA merupakan tahap yang penting didalam SEM karena pada tahap ini akan menguji apakah indikator- indikator yang digunakan benar-benar merupakan indikator dari konstruk laten tersebut.

1. Untuk menguji apakah konstruk laten variabel eksogen Developing effective network merupakan konstruk unidimensional yang didefinisikan oleh variabel observed DE1 - DE4 dapat digunakan analisis konfirmatori. Berdasarkan patokan sebuah indikator dapat diterima jika loading factor $>0,5$ maka hasil analisa konfirmatori faktor dari developing effective network sebagai berikut.

Tabel 3. Loading Factor variabel Developing effective

\begin{tabular}{ccc}
\multicolumn{3}{c}{ network } \\
\hline Indikator & Loading Factor & Keterangan \\
\hline DE1 & 0,83 & Valid \\
DE2 & 0,82 & Valid \\
DE3 & 0,87 & Valid \\
DE4 & 0,76 & Valid \\
\hline
\end{tabular}

2. Untuk menguji apakah konstruk laten variabel eksogen Supplier base reduction merupakan konstruk unidimensional yang didefinisikan oleh variabel observed SB1 - SB2 dapat digunakan analisis konfirmatori. Berdasarkan patokan sebuah indikator dapat diterima jika loading factor $>0,5$ maka hasil analisa konfirmatori faktor dari Supplier base reduction adalah sebagai berikut :

Tabel 4 . Loading Factor variabel Supplier base reduction

\begin{tabular}{ccc}
\hline Indikator & Loading Factor & Keterangan \\
\hline SB1 & 0,88 & Valid \\
SB2 & 0,79 & Valid \\
\hline
\end{tabular}

3. Untuk menguji apakah konstruk laten variabel eksogen longterm orientation merupakan konstruk unidimensional yang didefinisikan oleh variabel observed LO1 - LO4 dapat digunakan analisis konfirmatori. Berdasarkan patokan sebuah indikator dapat diterima jika loading factor $>0,5$ maka hasil analisa konfirmatori faktor dari longterm orientation adalah sebagai berikut :

Tabel 5 . Loading Factor variabel longterm orientation

\begin{tabular}{ccc}
\hline Indikator & Loading Factor & Keterangan \\
\hline LO1 & 0,85 & Valid \\
LO2 & 0,80 & Valid \\
LO3 & 0,81 & Valid \\
LO4 & 0,83 & Valid \\
\hline
\end{tabular}

4. Untuk menguji apakah konstruk laten variabel endogen supplier operational performance merupakan konstruk unidimensional yang didefinisikan oleh variabel observed SP1 - SP5 dapat digunakan analisis konfirmatori. Berdasarkan patokan sebuah indikator dapat diterima jika loading factor > 0,5 maka hasil analisa konfirmatori faktor dari supplier operational performance adalah sebagai berikut :

Tabel 6 . Loading Factor variabel supplier operational performance

\begin{tabular}{ccc}
\hline Indikator & Loading Factor & Keterangan \\
\hline SP1 & 0,85 & Valid \\
SP2 & 0,83 & Valid \\
SP3 & 0,87 & Valid \\
SP4 & 0,87 & Valid \\
SP5 & 0,76 & Valid \\
\hline
\end{tabular}

5. Untuk menguji apakah konstruk laten variabel endogen Organization operational performance merupakan konstruk unidimensional yang didefinisikan oleh variabel observed OP1 - OP7 dapat digunakan analisis konfirmatori. Berdasarkan patokan sebuah indikator dapat diterima jika loading factor > 0,5 maka hasil analisa konfirmatori faktor dari Organization operational performance adalah sebagai berikut:

Tabel 7. Loading Factor variabel Organization operational

\begin{tabular}{ccl}
\multicolumn{3}{c}{ performance } \\
\hline Indikator & Loading Factor & Keterangan \\
\hline OP1 & 0,59 & Valid \\
OP2 & 0,58 & Valid \\
OP3 & 0,62 & Valid \\
OP4 & 0,87 & Valid \\
OP5 & 0,91 & Valid \\
OP6 & 0,93 & Valid \\
OP7 & 0,93 & Valid \\
\hline
\end{tabular}

Berdasarkan tabel diatas semua indikator dinyatakan valid, berarti dapat dipakai untuk analisis selanjutnya.

\section{Structural Equation Modeling (SEM)}

Setelah model dianalisis melalui confirmatory factor analysis dan dapat dilihat bahwa masing-masing indikator dapat didifinisikan sebagai konstruk laten, maka sebuah full model SEM dapat dianalisis.

Pengujian structural equation model dilakukan dengan dua macam pengujian yaitu kesesuaian model serta uji signifikansi kausalitas melalui uji koefisien regresi seperti berikut ini:

1. Uji Kesesuaian Model-Goodness-of-fit Test

Uji terhadap kesesuaian model menunjukkan bahwa model ini sesuai atau fit terhadap data yang digunakan dalam penelitian. Hal ini terlihat dari kriteria yaitu: Chi-Square, Probabilty, CMIN/DF, TLI, CFI dan RMSEA semuanya diterima secara 
baik. Walaupun GFI dan AGFI nya masuk dalam kriteria marginal. Uji kesesuaian model terlihat dalam tabel 8 sebagai berikut:

Tabel 8. Uji Kesesuaian Model-Goodness-of-fit Test

\begin{tabular}{lccc}
\hline $\begin{array}{c}\text { Goodness of fit } \\
\text { Index }\end{array}$ & $\begin{array}{c}\text { Cut-off } \\
\text { Value }\end{array}$ & $\begin{array}{c}\text { Hasil } \\
\text { Model }\end{array}$ & Keterangan \\
\hline$\square$ 2-Chi-Square & $\begin{array}{c}\text { Diharapkan } \\
\text { Kecil }\end{array}$ & 407,897 & Marginal \\
Probability & $\geq 0,05$ & 0,000 & Marginal \\
CMIN/DF & $\square 2,00$ & 2,019 & Marginal \\
GFI & $\square 0,90$ & 0,757 & Marginal \\
AGFI & $\square 0,90$ & 0,696 & Marginal \\
TLI & $\square 0,95$ & 0,892 & Marginal \\
CFI & $\square 0,95$ & 0,906 & Marginal \\
RMSEA & $\square 0,08$ & 0,094 & Marginal \\
\hline
\end{tabular}

Dari tabel diatas dapat dijelaskan masingmasing indeks kesesuaian model sebagai berikut:

a. $\mathrm{c}^{2}-$ Chi-Square Statistic

Salah satu alat uji untuk mengukur overall fit adalah likelihood ratio Chi- square statistic. ChiSquare bersifat sangat sensitif terhadap besarnya sampel yang digunakan. Model yang akan diuji akan dipandang baik atau memuaskan bila nilai Chi-Square-nya rendah. Semakin kecil $c^{2}$ semakin baik model itu diterima berdasarkan probabilitas dengan cut off value sebesar $p>0,05$ (Ferdinand, 2005). Dalam penelitian ini nilai chisquare yang didapatkan adalah sebesar 407,897 dan nilai $p=0,000$, dengan demikian dapat disimpulkan bahwa model dalam penelitian ini termasuk marginal karena nilai chi-square hitung lebih kecil dari chi-square tabel dan nilai probability lebih kecil dari 0,050.

b. CMIN/DF - The Minimum Sample Discrepancy Function

CMIN/DF merupakan salah satu indikator untuk mengukur tingkat fitnya sebuah model (Ferdinand, 2005). Dalam hal ini CMIN/DF tidak lain adalah statistic-Chi-square, $\mathrm{c}^{2}$ dibagi DF-nya sehingga disebut $\mathrm{c}^{2}$ relatif. Nilai $\mathrm{c}^{2}$ relatif yang kurang dari 2,0 atau kurang dari 3,0 adalah indikasi dari acceptable fit antara model dan data (Ferdinand, 2005). Nilai CMIN/DF model penelitian ini adalah sebesar 2,019. Dengan demikian model ini termasuk a good fit, karena nilai $\mathrm{CMIN} / \mathrm{DF}=2,019$.

c. GFI - Goodness of Fit Index

GFI adalah sebuah ukuran non-statistikal yang mempuanyai rentang nilai antara 0 (poor fit) sampai dengan 1,0 (perfect fit). Nilai yang tinggi dalam indeks menunjukkan sebuah "better fit" dan suatu model dapat dikatakan very good jika nilai GFI-nya lebih dari atau sama dengan 0,90 . Nilai yang dihasilkan dalam penelitian ini adalah 0,757 sehingga tidak termasuk a very good fit, termasuk kriteria marginal karena GFI < 0,90.

d. AGFI-Adjusted Goodness-of Fit Index

AGFI adalah kriteria yang memperhitungkan proporsi tertimbang dari varians dalam sebuah matriks kovarians sampel. Tingkat penerimaan yang direkomendasikan adalah bila AGFI mempunyai nilai sama dengan atau lebih besar dari 0,90. Nilai sebesar 0,95 dapat di interprestasikan sebagai tingkatan yang baik-good overall model fit sedangkan besaran nilai antara 0,90 - 0,95 menunjukkan tingkatan cukupadequate fit. Nilai yang dihasilkan dalam penelitian ini adalah 0,696 sehingga tidak termasuk good overall model fit, termasuk kriteria marginal karena AGFI < 0,90.

e. TLI - Tucker Lewis Index

TLI adalah sebuah alternatif incremental fit index yang membandingkan sebuah model yang diuji terhadap sebuah baseline model. Nilai yang sangat mendekati 1 atau lebih dari 0,95 menunjukkan a very good fit (Ferdinand, 2005). Nilai TLI yang dihasilkan dalam penelitian ini adalah 0,892 sehingga dikategorikan termasuk $a$ very good fit, karena TLI $>0,95$.

f. CFI- Comparative Fit Index

Besaran indeks ini adalah pada rentang nilai 0 (poor fit) sampai dengan 1,0 (perfect fit). Nilai yang lebih atau sama dengan 0,95 mengidentifikasikan tingkat fit yang paling tinggi a very good fit (Arbuckle 1997, dalam Ferdinand, 2005). Nilai CFI yang dihasilkan dalam penelitian ini adalah 0,906 sehingga dikategorikan termasuk marginal.

g. RMSEA - The Root Mean Square Error of Approximation

RMSEA adalah alat uji lain menunjukkan goodness-of-fit yang dapat diharapkan bila model diestimasi dalam populasi (Ferdinand, 2005), Nilai RMSEA yang lebih kecil atau sama dengan 0,08 merupakan indeks untuk dapat diterimanya model yang menunjukkan sebuah close fit dari model itu berdasarkan degrees of freedom (Ferdinand, 2005).

Berdasarkan penelitian ini nilai RMSEA yang didapatkan adalah sebesar 0,094. Dengan demikian model ini adalah termasuk marginal.

2. Uji Kausalitas : Regression Test

Uji kausalitas yang dikembangkan dalam model ini, perlu diuji hipotesis nol yang menyatakan bahwa koefisien regresi antara hubungan adalah sama dengan nol melalui uji-t yang lazim dalam modelmodel regresi, nilai t identik C.R (Critical Ratio). Pengaruh Developing effective network, Supplier base reduction, Longterm orientation terhadap Supplier Operation Performance dan pengaruh 
Sri Sundari dan Cahyaningtyas Ria Uripi, Kapabilitas Membangun Jaringan dengan Pemasok untuk Meningkatkan Kinerja Operasional Pada Toko Aksesoris Telepon Genggam Di Kabupaten Banyumas

Supplier Operation Performance terhadap Organization Operational Performance adalah signifikan, karena probability nya $<0,05$

\section{Evaluasi Normalitas Data}

SEM mensyaratkan sebaiknya dipenuhi asumsi normalitas. Nilai statistik yang dapat digunakan untuk menguji normalitas adalah $z$-value. Nilai kritis yang biasa digunakan adalah $\square 2,58$, pada probability level 0,01 . Evaluasi untuk normalitas data terlihat nilai $\mathrm{CR}$ untuk skewness dan kurtosis secara univariate pada data semuanya lebih kecil dari $\square 2,58$. Hal ini berarti semua data memenuhi asumsi normalitas univariate pada $\square=$ 0,01 . Sementara itu, secara multivariate sebesar 2,827 yang lebih besar dari nilai kritis yang ditetapkan $(\square \square 2,58)$. Dengan demikian asumsi normalitas secara multivariate tidak terpenuhi, sehingga perlu dilakukan uji Bollen-Stine Bootstrap.

Hasil menunjukkan baha pada model original tanpa bootstrap nilai Chi square 407,897 dengan nilai probability 0,060. Berdasarkan hasil Bollen-Stine Bootstrap diperoleh nilai probability sebesar 0,238 yang lebih besar dari 0,05 sehingga model tidak dapat ditolak, dan hasil ini konsisten dengan hasil chi square model original yang juga tidak dapat menolak hiptesis nol. Sehingga antara model original dibandingan dengan model bootstrap masih konsisten, sehingga tidak normalnya data secara multivariate pada model empiris kedua masih dapat ditoleransi.

\section{Evaluasi Outliers}

\section{Univariate Outliers}

Dengan menggunakan dasar bahwa observasiobservasi yang mempunyai z- score $\pm 3,00$ akan dikategorikan sebagai outliers, diketahui bahwa data yang digunakan dalam penelitian ini adalah bebas dari univariate outliers.

\section{Multivariate Outliers}

Evaluasi terhadap multivariate outliers dapat dilihat dari jarak mahalanobis (the mahalanobis distance) untuk tiap-tiap variabel yaitu menunjukkan jarak sebuah variabel dari rata-rata semua variabel dalam sebuah ruang multidimensional (Ferdinand, 2005). Perhitungan jarak mahalanobis didasarkan pada nilai Chi-Square dalam tabel distribusi $\square^{2}$ pada derajat bebas sebesar 22 (jumlah indikator ) pada tingkat $\mathrm{p}<0,001$ yaitu $\square^{2}(22 ; 0,001=48,268)$. Oleh karena itu, data yang memiliki jarak mahalanobis lebih besar dari 48,268 dianggap multivariate outliers. Dalam analisis ini, multivariate outliers tidak ditemukan karena nilai pada mahalanobis distance lebih kecil dari 48,268.

3. Evaluasi Multicollinearity dan Singularity

Untuk melihat apakah terdapat multicollinearity dan singularity dalam sebuah kombinasi variabel, maka yang perlu diamati adalah nilai dari determinant of sample covariance matrix. Determinan yang sangat kecil mengindikasikan adanya multicollinearity dan singularity. Pada penelitian ini, nilai determinannya adalah 0,0000005568 atau dengan perhitungan dengan cara membagi jarak mahalanobis tertinggi $(38,768)$ dengan jumlah indikator (22), hasilnya adalah 1,76 lebih kecil dari 2,5 (Hair et al, 2010). Dengan demikian dapat disimpulkan bahwa tidak ada multicollinearity dan singularity, dengan demikian data dalam penelitian ini layak digunakan.

\section{Uji Reliability dan Variance Extract}

1. Uji Reliability

Reliability adalah ukuran mengenai konsistensi internal dari indikator- indikator sebuah konstruk yang menunjukkan derajat sampai dimana masingmasing indikator itu mengindikasikan sebuah konstruk yang umum (Ferdinand, 2005). Untuk menguji reliabilitas dilakukan dengan menghitung contruct (composite) reliabilitas ( $\square$ ) dari masingmasing konstruk yang diperoleh dari output pengujian model pengukuran yang dilakukan dengan program AMOS 22.00 (Ferdinand, 2005) memberikan formulasi untuk menghitung construct reliability dari suatu konstruk sebagai berikut :

$$
\text { Construct Reliability }=\frac{\left(\sum \text { standardized loading }\right)^{2}}{(\Sigma \text { standardized loading })^{2}+\sum \Sigma j}
$$

Standardized loading dapat diperoleh dari output Amos, dengan melihat nilai standardized regresion weight masing-masing konstruk terhadap indikatornya. Sementara itu $\square$ j dapat dihitung dengan formula $\square \mathrm{j}=1-(\text { standardized loading })^{2}$. Secara umum batas penerimaan composite reliability yaitu nilai koefisien $\square$ diatas 0,70 .

Tabel 9. Hasil Pengujian Construct Reliability

\begin{tabular}{lc}
\hline \multicolumn{1}{c}{ Construct } & $\mathrm{a}$ \\
\hline Developing effective network & 0,912 \\
Supplier base reduction & 0,926 \\
Longterm orientation & 0,931 \\
Supplier operational performance & 0,894 \\
Organization operational performance & 0,921 \\
\hline
\end{tabular}

Dari perhitungan construct reliability seperti pada tabel di atas, terlihat bahwa kelima konstruk laten yang digunakan dalam penelitian ini memiliki koefisien $\square$ lebih besar dari 0,70. dengan demikian dapat disimpulkan bahwa konstruk- konstruk laten yang digunakan dalam penelitian ini benar-benar reliabel.

2. Variance Extract

Variance Extract adalah ukuran yang menunjukkan jumlah variance dari indikator-indikator yang diekstraksi oleh konstruk laten yang dikembangkan (Ferdinand, 2005:95). Nilai variance extract yang tinggi menunjukkan bahwa indikator-indikator itu 
telah mewakili secara baik variabel laten yang dikembangkan. Dalam permodelan SEM, nilai batas yang digunakan untuk mengukur variance extract yang dapat diterima adalah $\square 0,50$ (Ferdinand, 2005). Adapun perhitungan varance extract dalam penelitian ini menggunakan rumus sebagai berikut: (Ferdinand, 2005).

Variance Extract $=\frac{\left(\sum \text { standardized loading }\right)^{2}}{(\Sigma \text { standardized loading })^{2}+\sum \Sigma j}$

Tabel 10. Hasil Pengujian Variance Extract

\begin{tabular}{lc}
\hline \multicolumn{1}{c}{ Construct } \\
\hline Developing effective network \\
Supplier base reduction & 0,762 \\
Longterm orientation & 0,723 \\
Supplier operational performance & 0,711 \\
Organization operational performance & 0,730 \\
\hline
\end{tabular}

Dari perhitungan variance exctract seperti pada tabel di atas, terlihat bahwa kelima konstruk laten yang digunakan dalam penelitian ini memiliki nilai batas $\square$ 0,50 dengan demikian dapat disimpulkan bahwa konstruk-konstruk laten yang digunakan dalam penelitian ini benar-benar reliabel.

\section{Uji Convergent Validity}

Indikator suatu konstruk laten harus converge atau share (berbagi) proporsi varian yang tinggi dan ini disebut convergent validity. Untuk mengukur validitas konstruk dapat dilihat dari nilai faktor loadingnya. Nilai loading yang tinggi pada suatu faktor menunjukkan bahwa mereka converge pada satu titik. Syarat yang harus dipenuhi adalah loading factor harus signifikan dan nilainya harus lebih besar dari 0,5 dan idealnya adalah 0,7. Berdasarkan hasil output standardized loading estimate maka loading factor dalam penelitian ini sudah diatas 0,5 sehingga dinyatakan valid.

\section{Pengujian Hipotesis}

1. Pengaruh developing effective network structures terhadap supplier operational performance.

Nilai C.R untuk pengaruh variabel developing effective network structures terhadap supplier operational performance pada tabel di atas sebesar 3,064 dengan $p$ value sebesar $0,004<0.05$. Dengan demikian hipotesis yang menyatakan bahwa developing effective network structures berpengaruh positif terhadap supplier operational performance dapat diterima. Hal ini menunjukkan bahwa indikator attribute performance value dapat meningkatkan supplier operational performance Toko aksesoris telepon genggam. Dengan demikian semakin tinggi developing effective network structures maka semakin tinggi supplier operational performance supplier operational performance Toko aksesoris telepon genggam dan sebaliknya.
2. Pengaruh supplier base reduction terhadap supplier operational performance

Nilai C.R untuk pengaruh variabel supplier base reduction terhadap supplier operational performance pada tabel di atas sebesar 2,354 memiliki $p$ value sebesar $0,017<0,05$. Dengan demikian hipotesis yang menyatakan bahwa supplier base reduction berpengaruh positif terhadap supplier operational performance diterima. Hal ini menunjukkan bahwa indikator supplier base reduction dapat meningkatkan supplier operational performance Toko aksesoris telepon genggam. Dengan demikian semakin tinggi supplier base reduction maka semakin tinggi supplier operational performance Toko aksesoris telepon genggam dan sebaliknya.

3. Pengaruh longterm orientation terhadap supplier operational performance

Nilai C.R untuk pengaruh variabel longterm orientation terhadap supplier operational performance pada tabel di atas sebesar 3,175 memiliki $p$ value sebesar $0,028<0,05$. Dengan demikian hipotesis yang menyatakan bahwa longterm orientation berpengaruh positif dan signifikan terhadap supplier operational performance diterima. Hal ini menunjukkan bahwa indikator orientation dapat meningkatkan supplier operational performance Toko aksesoris telepon genggam. Dengan demikian semakin tinggi orientation maka semakin tinggi supplier operational performance Toko aksesoris telepon genggam dan sebaliknya.

4. Pengaruh supplier operational performance terhadap organization operational performance

Nilai C.R untuk pengaruh variabel supplier operational performance terhadap organization operational performance pada tabel di atas sebesar 4,103 dengan $p$ value sebesar $0,000<0,05$. Dengan demikian hipotesis yang menyatakan bahwa supplier operational performance berpengaruh positif terhadap organization operational performance dapat diterima. Hal ini menunjukkan bahwa indikator supplier operational performance dapat meningkatkan organization operational performance Toko aksesoris telepon genggam. Dengan demikian semakin tinggi supplier operational performance supplier operational performance maka semakin tinggi organization operational performance Toko aksesoris telepon genggam dan sebaliknya.

\section{Pembahasan}

1. Pengaruh developing effective network structures terhadap supplier operational performance

Hasil penelitian menunjukkan bahwa developing effective network structures berpengaruh positif terhadap supplier operational performance. Toko Aksesoris telepon genggam mempunyai kemampuan Menjalin komunikasi yang baik dengan pemasok yang baik, hal ini dapat dibuktikan dengan hasil 
statistik deskriptif untuk indikator memastikan kepuasan konsumen terhadap produk rata-ratanya adalah sebesar 5,27 yang berarti kategori jawaban yang baik. Hubungan didasari saling membutuhkan dengan rata- rata sebesar 5,19 dengan kategori baik. Karakteristik jaringan meningkatkan nilai tambah dan struktur jaringan tidak melibatkan kekuasaan. Hal tersebut akan meningkatkan fleksibilitas volume, fleksibilitas jadwal, pengiriman dari supplier tepat waktu, konsistensi pengiriman oleh supplier, dan kualitas yang baik toko aksesoris telepon genggam. Hasil penelitian ini sejalan dengan penelitian yang dilakukan oleh Chen and Paulraj (2004) dan Kandemir and Cavusgil (2006) yang menemukan bahwa variabel developing effective network structures berpengaruh positif terhadap supplier operational performance.

2. Pengaruh supplier base reduction terhadap supplier operational performance

Hasil penelitian menunjukkan bahwa supplier base reduction berpengaruh positif terhadap supplier operational performance. Toko aksesoris telepon genggam Melakukan hubungan hanya dengan pemasok berkualitas tinggi dan menjaga hubungan dengan pemasok tertentu sehingga akan meningkatkan fleksibilitas volume, fleksibilitas jadwal, pengiriman dari supplier tepat waktu, konsistensi pengiriman oleh supplier, dan kualitas yang baik toko aksesoris telepon genggam. Hasil penelitian ini sejalan dengan penelitian yang dilakukan oleh Chen and Paulraj (2004) dan Kandemir and Cavusgil (2006) yang menemukan bahwa variabel supplier base reduction berpengaruh positif terhadap supplier operational performance.

3. Pengaruh longterm orientation terhadap supplier operational performance

Hasil penelitian menunjukkan bahwa longterm orientation berpengaruh positif terhadap supplier operational performance. Toko aksesoris telepon genggam melakukan hubungan yang bertahan lama, hubungan untuk meningkatkan kualitas jangka panjang, pemasok menganggap hubungan sebagai aliansi jangka panjang, dan toko aksesoris menganggap pemasok kepanjangan perusahaan sehingga akan meningkatkan fleksibilitas volume, fleksibilitas jadwal, pengiriman dari supplier tepat waktu, konsistensi pengiriman oleh supplier, dan kualitas yang baik toko aksesoris telepon genggam. Hasil penelitian ini sejalan dengan penelitian yang dilakukan oleh Chen and Paulraj (2004) dan Kandemir and Cavusgil (2006) yang menemukan bahwa variabel longterm orientation berpengaruh positif terhadap supplier operational performance.

4. Pengaruh supplier operational performance pada organization operational performance

Hasil penelitian menunjukkan bahwa supplier operational performance berpengaruh positif terhadap organization operational performance. Toko aksesoris telepon genggam mempunyai fleksibilitas volume, fleksibilitas jadwal, pengiriman dari supplier tepat waktu, konsistensi pengiriman oleh supplier, dan kualitas yang baik sehingga meningkatkan fleksibilitas volume, kecepatan pelayanan, keandalan pelayanan, kesesuaian produk dengan spesifikasi, konfirmasi pesanan cepat, penanganan masalah cepat dan kepuasan pelanggan toko aksesoris telepon genggam. Hasil penelitian ini sejalan dengan penelitian yang dilakukan oleh Chen and Paulraj (2004) dan Kandemir and Cavusgil (2006) yang menemukan bahwa variabel supplier operational performance berpengaruh positif terhadap organization operational performance.

\section{SIMPULAN}

Hasil penelitian menunjukkan bahwa 1) developing effective network structures berpengaruh positif terhadap supplier operational performance, hal ini dibuktikan dengan nilai $p<0,05$ yang berarti semakin tinggi Developing effective network structures maka semakin tinggi supplier operational performance. 2) supplier base reduction berpengaruh positif terhadap supplier operational performance, hal ini dibuktikan dengan nilai $p<0,05$ yang berarti semakin tinggi supplier base reduction maka semakin tinggi supplier operational performance. 3) longterm orientation berpengaruh positif terhadap supplier operational performance, hal ini dibuktikan dengan nilai $p<0,05$ yang berarti semakin tinggi longterm orientation maka semakin tinggi supplier operational performance. Dan 4) supplier operational performance berpengaruh positif terhadap organization operational performance, hal ini dibuktikan dengan nilai $p<0,05$ yang berarti semakin tinggi Supplier operational performance maka semakin tinggi organization operational performance. Temuan ini mengimplikasikan kebijakan manajerial: 1) toko aksesoris telepon genggam perlu terus meningkatkan kemampuan menjalin jaringan yang efektif dengan pemasok, hubungan didasari oleh saling membutuhkan, untuk meningkatkan nilai tambah yang fleksibel, struktur jaringan tidak melibatkan hubungan berbasis kekuasaan. 2) toko aksesoris telepon genggam perlu mengurangi hubungan yang tidak menguntungkan dengan pemasok, melakukan hubungan hanya yang berkualitas tinggi dengan pemasok tertentu. 3) toko aksesoris telepon genggam perlu meningkatkan kemampuan menjalin jaringan jangka panjang untuk meningkatkan kualitas dalam jangka panjang, menganggap pemasok sebagai kepanjangan tangan perusahaan karena hal tersebut mempengaruhi kinerja hubungan dengan pemasok. Dan 4) toko aksesoris telepon genggam perlu meningkatkan kinerja operasional yang dihasilkan dari hubungan dengan pemasok karena hal tersebut mempengaruhi kinerja operasional perusahaan. 


\section{DAFTAR PUSTAKA}

Barney, J. (1991). Firm resources and sustained competitive advantage. Journal of management, 17(1), 99-120.

Chen, I. J., \& Paulraj, A. (2004). Towards a theory of supply chain management: the constructs and measurements. Journal of operations management, 22(2), 119-150.

Day, G. S. (1994). The capabilities of market-driven organizations. Journal of marketing, 58(4), 37-52.

Kandemir, D., Yaprak, A., \& Cavusgil, S. T. (2006). Alliance orientation: conceptualization, measurement, and impact on market performance. Journal of the academy of marketing science, 34(3), 324-340.

Kotabe, M., Martin, X., \& Domoto, H. (2003). Gaining from vertical partnerships: knowledge transfer, relationship duration, and supplier performance improvement in the US and Japanese automotive industries. Strategic management journal, 24(4), 293-316.

Mort, G. S., \& Weerawardena, J. (2006). Networking capability and international entrepreneurship: How networks function in Australian born global firms. International Marketing Review, 23(5), 549-572.

Suliyanto, S. (2006). Metode Riset Bisnis. Penerbit CV. Andi Offset, Yogyakarta.

Stanley, L. L., \& Wisner, J. D. (2001). Service quality along the supply chain: implications for purchasing. Journal of operations management, 19(3), 287-306.

Teece, D. J., Pisano, G., \& Shuen, A. (1997). Dynamic capabilities and strategic management. Strategic management journal, 18(7), 509-533.

Wernerfelt, B. (1984). A resource-based view of the firm. Strategic management journal, 5(2), 171180. 